\title{
Effect of carbon surface on degradation of supercapacitors in a
}

\section{negative potential range}

Rui Tang, ${ }^{1}$ Masanori Yamamoto, ${ }^{1}$ Keita Nomura, ${ }^{1}$ Emilia Morallón, ${ }^{2}$ Diego Cazorla-Amorós, ${ }^{2}$ Hirotomo Nishihara, ${ }^{* 1}$ Takashi Kyotani ${ }^{1}$

${ }^{1}$ Institute of Multidisciplinary Research for Advanced Materials, Tohoku University, 2-1-1

Katahira, Aoba-ku, Sendai, Miyagi, 980-8577, Japan

${ }^{2}$ Instituto Universitario de Materiales, Universidad de Alicante, Apartado 99, 03080, Alicante, Spain

*Corresponding author

Tel: $+81-22-217-5627$

Fax: $+81-22-217-5626$

E-mail: hirotomo.nishihara.b1@tohoku.ac.jp 


\begin{abstract}
The stability of supercapacitors is the key factor for their use under high temperature and high voltage conditions, and also for long-term durability. To improve the supercapacitor stability, understanding of the degradation mechanism is essential. In this work, the degradation sites in a carbon electrode at negative potential range are investigated in two types of common organic electrolytes, $1 \mathrm{M} \mathrm{Et}_{4} \mathrm{NBF}_{4}$ dissolved in propylene carbonate and in acetonitrile. To elucidate the common factor over a wide range of carbon materials, eight kinds of very different carbon materials are examined, including four activated carbons, two carbon blacks, zeolite-template carbon (high surface area and a large amount of carbon edge sites) and graphene mesosponge (high surface area and a little amount of carbon edge sites). Their surface structures are distinguished into two regions: carbon basal planes and edge sites, by the characterization techniques of nitrogen physisorption and high-sensitivity temperature-programmed desorption up to $1800{ }^{\circ} \mathrm{C}$. Unlike the degradation at positive potential range, degradation reactions at negative potential range occur mainly on the carbon basal planes rather than the edge sites, and this is corroborated by the theoretical calculation.
\end{abstract}

Keywords: supercapacitors; electrochemical degradation; negative potential range; edge site; basal plane 


\section{Introduction}

Electric double-layer capacitors, also called supercapacitors, are energy storage devices based on the mechanism of reversible electrostatic adsorption of ions on the electrolyte-electrode interface.[1] Supercapacitors are featured by high power density and long cycle life,[2] and have been widely used in many applications such as automobiles, backup systems,[3] screwdrivers, and electric cutters.[4] For most of commercial supercapacitors, activated carbons with high surface area $\left(\sim 2000 \mathrm{~m}^{2} \mathrm{~g}^{-1}\right)$ are used as an electrode material, together with organic electrolytes with a low viscosity and a relatively wide potential window, such as tetraethylammonium tetrafluoroborate $\left(\mathrm{Et}_{4} \mathrm{NBF}_{4}\right)$ dissolved in propylene carbonate $(\mathrm{PC})$ or in acetonitrile (AN). Supercapacitors using these organic electrolytes are usually operated within a certain voltage range $(<2.8 \mathrm{~V})$ and temperature range $\left(-40\right.$ to $\left.70{ }^{\circ} \mathrm{C}\right)$ to avoid significant degradation reactions causing capacitance drop,[5] resistance increase,[5] and gas evolution.[6] Nevertheless, the degradation reactions progress very slowly, and supercapacitors thus have a finite cycle life of 500,000 to 1,000,000,[2] depending on operating temperature.[7-9] It is generally known that the life of supercapacitors becomes half when the temperature rises by $10{ }^{\circ} \mathrm{C}$. Thus, the improvement of the supercapacitor stability is an important issue in industry for extending both cycle life and temperature range.[10] Moreover, better stability enables the expansion of voltage range, which is important from the following two reasons. First, the increase of working voltage $(V)$ is effective to achieve high energy density $(E)$, according to the formula, $E=C V^{2} / 2$, where $C$ is capacitance. Second, by increasing $V$ of a single cell, the cell-stacking number can be decreased in high-voltage modules consisting of a number of single cells, enabling the development of compact devices. $[8,11]$

To improve supercapacitor stability, it is crucial to understand the degradation mechanism. It 
has been known that severe degradation reactions produce gases[6, 12, 13] and polymer depositions[14]. The gas products increase the inner pressure of supercapacitor, leading to the risk of cell breakage.[15] Moreover, the polymer depositions increase the inner cell resistance and block carbon nanopores, giving rise to the decline of rate capability and capacitance.[5, 16] These degradation reactions occur at the interface of carbon electrode and electrolyte. As for the electrolyte side, many groups have reported the decomposition of electrolyte solvents $[2,6,17,18]$ and electrolyte salts, $[5,17,19,20]$ based on the results obtained by X-ray photoelectron spectroscopy, $[5,17,21]$ nuclear magnetic resonance spectroscopy,[5] infrared spectroscopy,[17] gas chromatography,[12, 19] mass spectrometry,[6] energy dispersion Xray fluorescence spectroscopy,[14] and scanning electron microscopy.[14] On the other hand, there have been not many papers reporting the origin of degradation reactions at the carbon electrode side in organic electrolytes which are used for commercial supercapacitors. Azaïs et $a l$ have proposed that carbon porosity does not affect the stability of supercapacitors but surface functionalities play an important role instead.[5] This is further supported by works done by other groups.[12, 13, 16] However, these previous works used a limited types of carbon materials, and their conclusions therefore cannot cover a variety of different carbon materials. Moreover, specific carbon sites responsible for the degradation have not been separately explored at positive and negative potential ranges. Under such background, our group has systematically investigated the effect of carbon structure (porosity, crystallinity, radicals and edges) on the degradation reactions at a positive potential range. By using a variety of very different carbon materials, we have elucidated that the degradation-causing sites in carbon materials are carbon edge sites which are terminated by hydrogen $(H)$ or oxygen $(\mathrm{O})$ in the forms of phenol, ether, and carbonyl groups.[18]

In this work, the degradation-causing sites in carbon materials are investigated at a negative potential range in the two commonly used electrolyte solutions, $\mathrm{Et}_{4} \mathrm{NBF}_{4} / \mathrm{PC}$ and 
$\mathrm{Et}_{4} \mathrm{NBF}_{4} / \mathrm{AN}$. To elucidate the degradation-causing sites which are common to a variety of different carbon materials, eight very different carbon materials are selected, including four activated carbons, two carbon blacks, zeolite-template carbon (ZTC; high surface area and a large amount of carbon edge sites)[22] and graphene mesosponge (GMS; high surface area and a small amount of carbon edge sites).[23] Since the degradation reactions occur at the interface of carbon and an electrolyte solution, the degradation-causing sites must exist on the carbon surface. However, we have previously found that the specific surface area has almost no correlation with the degradation at the positive potential range.[18] In this work, we revisit the effect of specific surface area, and find that the surface area which corresponds to only the carbon basal planes (but not to the edge planes) does affect the degradation reactions at the negative potential range. Such different reactivities on the basal planes and the edge sites are further discussed with theoretical calculations.

\section{Methods}

\subsection{Carbon materials}

Eight kinds of carbon materials were used in this work, including four kinds of activated carbons, two kinds of carbon blacks, ZTC [22] and GMS [23]. The information of the carbon materials is listed in Table 1. Activated carbons (Fig. 1a) are highly porous, being mainly composed of disordered $s p^{2}$-hybridized carbon frameworks which differ depending on the carbon precursors and preparation conditions. Carbon blacks (Fig. 1b) are spherical particles with diameters of several tens nanometers, and the spheres consist of stacked small carbon layers.[24] Carbon blacks have a smaller amount of carbon edge sites than activated carbons, while the surface areas of the former carbons are lower. ZTC (Fig. 1c) is an ordered microporous carbon comprised of single-layer graphene framework, and thus ZTC has the highest surface area in Table 1, whereas it has a very large amount of edge sites. GMS (Fig. 
1d) is made up of curved single-walled graphene with a very small amount of carbon edge sites.

\subsection{Characterization}

Nitrogen adsorption isotherms of the carbon materials were measured at $-196^{\circ} \mathrm{C}$ by using a BELSORP-max instrument (MicrotracBEL Corp.). The specific surface area $\left(S_{\alpha}\right)$ was calculated by the subtracting pore-effect method[25] based on the $\alpha_{s}$ plot. Since $S_{\alpha}$ provides accurate surface area without the effect of micropore filling, it is more reliable especially for microporous materials than the one calculated by the Brunauer-Emmett-Teller method (called BET surface area).[26] The carbon edge sites were characterized by the highsensitivity TPD method which had been developed by our group.[27] During the TPD measurement, ca. $1 \mathrm{mg}$ of carbon material was heated up to $1800{ }^{\circ} \mathrm{C}$ with a heating rate of 10 ${ }^{\circ} \mathrm{C} \mathrm{min}{ }^{-1}$ under high vacuum (ca. $1 \times 10^{-5} \mathrm{~Pa}$ ). The H-terminated sites and oxygen functional groups at carbon edge sites are thermally decomposed as $\mathrm{H}_{2}, \mathrm{H}_{2} \mathrm{O}, \mathrm{CO}_{2}$ and $\mathrm{CO}$ gases and they are quantified by a mass spectrometer.[18] Since almost all the edge sites terminated by $\mathrm{H}$ or oxygen functional groups are decomposed as the aforementioned gases below $1800{ }^{\circ} \mathrm{C}$, it is possible to calculate the total amount of these edge sites $\left(N_{\text {edge }}\left[\mathrm{mmol} \mathrm{g}^{-1}\right]\right)$ according to the following equation:

$$
N_{\text {edge }}=N_{\mathrm{CO}}+N_{\mathrm{CO} 2}+N_{\mathrm{H} 2 \mathrm{O}}\left(>400^{\circ} \mathrm{C}\right)+2 \times N_{\mathrm{H} 2}
$$

where $N_{\mathrm{CO}}, N_{\mathrm{CO} 2}$, and $N_{\mathrm{H} 2}$ are entire desorption amounts $\left(\mathrm{mmol} \mathrm{g}{ }^{-1}\right)$ of $\mathrm{CO}, \mathrm{CO}_{2}$, and $\mathrm{H}_{2}$, respectively, during the TPD measurement. $N_{\mathrm{H} 2} \mathrm{O}\left(>400{ }^{\circ} \mathrm{C}\right)$ is the $\mathrm{H}_{2} \mathrm{O}$ desorption amount in TPD above $400{ }^{\circ} \mathrm{C}$, because the $\mathrm{H}_{2} \mathrm{O}$ desorption below $400{ }^{\circ} \mathrm{C}$ corresponds to physisorbed water or the desorption by dehydration of two carboxyl groups.[18] $N_{\mathrm{H} 2}$ is multiplied by 2 because $1 \mathrm{~mol}$ of $\mathrm{H}_{2}$ originates from $2 \mathrm{~mol}$ of $\mathrm{H}$-terminated edge sites. Since $\mathrm{H}_{2}$ may also 
originate from phenol groups (H-terminated edge sites are left after the thermal decomposition of phenols as $\mathrm{CO}$ gases), the calculation of $N_{\text {edge }}$ may be overestimated as the phenol groups are double counted. However, according to our calculation (shown in Fig. S1 and Table. S1), this overestimation has a small effect on the calculation of $N_{\text {edge, }}$ and we thus neglect the effect. On the other hand, free edge sites like $\sigma$-radicals and triplet carbenes[28] are not considered in equation (1), thus $N_{\text {edge }}$ may be underestimated. In order to estimate the amount of free edge sites, we compared $N_{\text {edge }}$ with our previous results obtained by magnetic susceptibility measurement which can determine the spin density in the used carbon materials.[18] There are three possible origins for spin, including $\sigma$-radicals, triplet carbenes and $\pi$-radicals[29]. Considering the high reactivity of $\sigma$-radicals and the fact that the carbons we used are exposed in air, it is reasonable to ascribe most of the observed spin to triplet carbenes and $\pi$-radicals. However, the presence of $\pi$-radicals does not cause the underestimation of $N_{\text {edge, }}$ because $\pi$-radicals are always formed at H-terminated edge sites which can be detected by TPD. Then, the maximum amount of free edge sites can be calculated by assuming all the spin comes from triplet carbenes. However, according to our calculation (shown in Table. S2), this underestimation is very small for the calculation of $N_{\text {edge. }}$ By using the resulting $N_{\text {edge, }}$ we then estimated the edge-site surface area $\left(S_{\text {edge }}\right)$ by assuming that the area occupied by each edge site is $0.083 \mathrm{~nm}^{2}$.[30] By subtracting $S_{\text {edge }}$ from $S_{\alpha}$, basal-plane surface area $\left(S_{\text {basal }}\right)$ was calculated and they are shown in Table 2.

\subsection{Electrochemical measurement}

The irreversible process occurring on carbon electrode was quantitatively characterized by cyclic voltammetry $(\mathrm{CV})$ with a designed sequence using a three-electrode cell at $25^{\circ} \mathrm{C}$ and ..... potentiostat.[31] A working electrode was prepared in the following manner. A carbon sample was mixed with a binder polymer (PTFE; PTFE 6-J, Du Pont-Mitsui Fluorochemicals 
Co. Ltd.) and a conductive additive (Denka black, Denki Kagaku Kogyo Kabushiki Kaisha) at the weight ratio of 90:5:5. For two carbon black samples (XC72 and KB), a sample was mixed with PTFE at the weight ratio of $85: 15$ without the conductive additive, because a relatively large amount of PTFE is necessary to prepare a uniform electrode sheet and carbon blacks have enough high electric conductivity. The resulting mixture was pressed to form a sheet, and it was cut out as a square shape $\left(1 \times 1 \mathrm{~cm}^{2}, 5-10 \mathrm{mg}\right)$, which was sandwiched by a Pt mesh to be a working electrode. The electrolyte was $1 \mathrm{M} \mathrm{Et}_{4} \mathrm{NBF}_{4}$ dissolved in PC or AN. An activated carbon fiber (Kuraray Chemical Co., Ltd., FT300-15) was used for the counter electrode, which was prepared in the same manner as that for the working electrode except for its loading amount (ca. $20 \mathrm{mg}$ ). The reference electrode was $\mathrm{Ag} / \mathrm{AgClO}$. With the threeelectrode cell, CV was performed in the following manner. First, CV scan $\left(1 \mathrm{mV} \mathrm{s}^{-1}\right)$ was repeated four times in the potential range of -1.0 to $0 \mathrm{~V}$, and then the lower potential limit was stepwisely expanded by $0.1 \mathrm{~V}$ down to $-2.1 \mathrm{~V}$. In each potential range, $\mathrm{CV}$ scan was repeated four times. The degradation of the carbon electrode was judged by irreversible charge $\left(Q_{\text {ir-neg }}\left[\mathrm{C} \mathrm{g}^{-1}\right]\right),[18]$ calculated by the following equation:

$$
Q_{\text {ir-neg }}=Q_{-}-Q_{+}
$$

where $Q_{-}$and $Q_{+}$are the total charges during the negative-direction scan and the positivedirection scan, respectively, in the first CV measurement at a certain potential range (an example is shown in Fig. 2a). The degradation at the positive potential range was also examined by similar CV measurements, in which the initial potential range of -0.5 to $0.5 \mathrm{~V}$ was stepwisely expanded to the positive potential by $0.1 \mathrm{~V}$ up to $1.3 \mathrm{~V}$. The irreversible charge in positive potential range $\left(Q_{\mathrm{ir}-\text { pos }}\left[\mathrm{C} \mathrm{g}^{-1}\right]\right)$ was calculated by the following equation:

$$
Q_{\text {ir-pos }}=Q_{+}-Q_{-}
$$




\subsection{Computational chemistry}

Carbon basal planes and edge planes are quite different in their chemical nature; the former have abundant $\pi$-electrons while the latter are featured by covalent bonds with hydrogen or oxygen. As such, their interaction with electrochemical reactants may also be markedly different. To obtain the insight at the molecular level, the density functional theory (DFT) calculation for the pair of a carbon model and a reactant was also performed to estimate the energy level and the overlapping of each molecular orbitals. The calculations were carried out on an open-shelled carbon model (hexabenzocoronene) and acetonitrile (instead of PC or ions, AN is selected due to its simple structure which can avoid the geometry effect of reactants during the calculation) as a representative of reactant by using the Gaussian 16 package of program[32] with the range-separated hybrid functional of $\omega \mathrm{B} 97 \mathrm{XD}[33,34]$ together with $6-311++\mathrm{G}^{*}$ basis set for hydrogen, carbon and nitrogen atoms. For the geometry optimization of acetonitrile at the edge of the carbon model, the nitrogen atom was fixed within the co-plane of the carbon model. Time-dependent DFT (TD-DFT) calculation was also carried out at the same level of theory with the long-range corrected $\omega \mathrm{B} 97 \mathrm{XD}$ functional. Solvent effects were considered in an implicit solvent model COSMO[35] (or cubity PCM, CPCM) with acetonitrile as a solvent for all calculations. The frequency analyses were then carried out at the same level of theory to check whether there is an imaginary vibrational mode or not, and the results were used to determine the thermodynamics.

\section{Results and discussion}

\subsection{Degradation behaviours of eight carbon materials}

Fig. $2 \mathrm{~b}$ and c show the CV results of YP50F in the two organic electrolytes. In both cases, 
when the lower limit potential is $-1.0 \mathrm{~V} v \mathrm{~s} . \mathrm{Ag} / \mathrm{AgClO}$, the overall shape of $\mathrm{CV}$ curve is almost symmetrical to the $\mathrm{x}$-axis, indicating that the current observed is derived from the reversible process, i.e., electric double-layer capacitance. As the lower limit potential is expanded to the more negative direction (to the left), the CV shape is gradually warped by the greater cathodic current at the low potential region, suggesting the occurrence of irreversible reactions. The same tendency is found also in the other carbon samples (Fig. S2 and S3). The charge of the irreversible reactions is quantitatively obtained as $Q_{\mathrm{ir}-\mathrm{neg}}$, calculated by the method shown in Fig. 2a.[31]

Fig. 3a and c show the change of $Q_{\text {ir-neg }}$ with the lower potential limit for the eight carbon materials. As a general tendency, $Q_{\text {ir-neg }}$ is gradually increased below $-1.2 \mathrm{~V}$ for all the carbon materials, while the value of $Q_{\text {ir-neg }}$ highly depends on the type of carbon material. Also, the change of $Q_{\text {ir-pos }}$ with the upper potential limit is shown in Fig. $3 \mathrm{~b}$ and d. Previously, a part of the results shown in Fig. 3b were already reported by our group without the data of GMS and MSC30.[18] Commercial supercapacitors are usually assembled with the symmetric configuration. When such a symmetrical supercapacitor is charged, the potential difference of each electrode from the open circuit potential (OCP) is almost even. Considering that the $\mathrm{OCP}$ of the eight carbon materials is about $-0.1 \mathrm{~V}$ vs. $\mathrm{Ag} / \mathrm{AgClO}$, the potentials of positive and negative electrodes at a fully-charged state (2.8 V for commercial supercapacitors) correspond to 1.3 and $-1.5 \mathrm{~V}$, respectively. As Fig. 3 shows, $Q_{\text {ir-pos }}$ at $1.3 \mathrm{~V}$ is much larger than $Q_{\text {ir-neg }}$ at $-1.5 \mathrm{~V}$ for all the carbons, indicating that the degradation at the positive side is much more significant than that at the negative side. This finding is consistent with the previous reports, where electrochemical degradation results in greater loss of porosity at the positive electrodes than that at the negative electrodes. $[5,16,17]$

3.2. Difference in the electrochemical degradation between positive and negative potential 
ranges

For the degradation at the positive potential, we have previously reported a clear correlation between $Q_{\text {ir-pos }}$ and the amount of the specific edge sites which are terminated with $\mathrm{H}$, phenol, ether, and carbonyl groups, expressed by $2 N_{\mathrm{H} 2}+N_{\mathrm{CO}}$.[18] Thus, we first tried to find a correlation also between $Q_{\text {ir-neg }}$ and $2 N_{\mathrm{H} 2}+N_{\mathrm{CO}}$. As shown in Fig. $4 \mathrm{a}$ and c, however, no good correlation is found. Note that there is also no correlation between $Q_{\text {ir-neg }}$ and $N_{\mathrm{CO}}, N_{\mathrm{CO} 2}, N_{\mathrm{H} 2 \mathrm{O}}$ nor $N_{\mathrm{H} 2}$ (Fig. S4 and Fig. S5). This means that one or several specific carbon edge sites are not responsible for the degradation in the present negative potential ranges. On the other hand, $Q_{\text {ir-pos }}$ of the eight carbon materials shows a linear dependence on $2 N_{\mathrm{H} 2}+N_{\mathrm{CO}}$ (Fig. $4 \mathrm{~b}$ and d). Previously, such a linear correlation between $Q_{\text {ir-pos }}$ (at an upper potential limit of 1.0 V) and $2 N_{\mathrm{H} 2}+N_{\mathrm{CO}}$ was already reported by our group, without the data of GMS and MSC30.[18] It should be noted that the linear correlation of Fig. 4b still exists even without ZTC.[18] These results suggest the different mechanisms of degradation reactions at the negative and positive potential ranges. To figure out an important factor at the negative potential range, we focus on the two carbons in Fig. 3 as extreme models: ZTC with large surface area and a large amount of edge sites, and GMS with large surface area and a very few amount of edge sites. For $Q_{\text {ir-pos }}$ (Fig. 3b, d), the degradation-causing sites locate at the carbon edge sites, and therefore, ZTC shows large $Q_{\text {ir-pos, }}$ whereas GMS shows small $Q_{\text {ir-pos. }}$. On the other hand, for $Q_{\text {ir-neg }}$ (Fig. 3a, c), both ZTC and GMS show large $Q_{\text {ir-neg. Thus, it is }}$ very likely that the degradation at the negative potential range depends on the surface area rather than edge sites.

\subsection{The effect of different types of carbon surface}

From the above discussion, it is worth checking the relation between $Q_{\text {ir-neg }}$ and carbon surface area, which can be characterized by nitrogen adsorption isotherm. Although the BET 
method is popularly used to estimate specific surface areas of carbon materials, this method causes noticeable errors when applied to microporous materials in which the micropore filling (the different adsorption mechanism from the multi-layer adsorption) occurs.[36] Alternatively, we used the pore-effect subtracting method, [25] which is based on the $\alpha_{s}$-plot, to estimate more accurate specific surface areas $\left(S_{\alpha}\right)$. The comparison between BET surface area and $S_{\alpha}$ is shown in Table S3. Fig. 5a and b show $Q_{\text {ir-neg }}$ of each carbon plotted against $S_{\alpha}$ in the PC-based and AN-based electrolytes. Compared to Fig. 4a and c, much better correlations are obtained, especially in $1 \mathrm{M} \mathrm{Et}_{4} \mathrm{NBF}_{4} / \mathrm{PC}$.

It should be noted that $S_{\alpha}$ contains two different types of contributions: basal planes and edge sites. Since the latter has nothing to do with carbon degradation (Figs. 4a, c, S4 and S5), probably only the basal plane may cause carbon degradation. To clarify this point, the total surface area $\left(S_{\alpha}\right)$ should be divided into basal-plane surface area $\left(S_{\text {basal }}\right)$ and edge-site surface area $\left(S_{\text {edge }}\right)$. The high-sensitive TPD up to $1800^{\circ} \mathrm{C}$ enables the quantitative determination of carbon edge sites $\left(N_{\text {edge }}\left[\mathrm{mmol} \mathrm{g}^{-1}\right]\right.$, shown in Table 1$)$, and $S_{\text {edge }}$ was calculated by assuming that the area occupied by each edge site is $0.083 \mathrm{~nm}^{2}$.[30] Once $S_{\text {edge }}$ is obtained, $S_{\text {basal }}$ can be easily calculated by subtracting $S_{\text {edge }}$ from $S_{\alpha}$. The results are shown in Table 2. Thus, $Q_{\text {ir-neg }}$ is plotted against $S_{\text {edge }}$ (Fig. 5c, d) and $S_{\text {basal }}$ (Fig. 5e, f). As already revealed in Figs. 4a, b, S4 and S5, $Q_{\text {ir-neg }}$ shows no correlation with $S_{\text {edge. }}$ On the other hand, a positive correlation is found between $Q_{\text {ir-neg }}$ and $S_{\text {basal }}$ as shown in Fig. 5e and f. The correlation coefficients $\left(R^{2}\right)$ in Fig. 5e and $\mathrm{f}\left(Q_{\text {ir-neg }}\right.$ versus $\left.S_{\text {basal }}\right)$ are better than those in Fig. 5a and b ( $Q_{\text {ir-neg }}$ versus $\left.S_{\alpha}\right)$, indicating that basal planes are responsible for the electrochemical degradation in the negative potential range.

3.4. The dependence of correlation on potential

While the above discussion is based on $Q_{\text {ir-neg }}$ at $-1.5 \mathrm{~V}$ vs. $\mathrm{Ag} / \mathrm{AgClO} 4$, we discuss here how 
the correlation varies with the potential. The correlation coefficients $\left(R^{2}\right)$ between $Q_{\text {ir-neg }}$ and different carbon surfaces $\left(S_{\alpha}, S_{\text {basal }}\right.$ and $\left.S_{\text {edge }}\right)$ with the different lower potential limits are summarized in Fig. 6. For both electrolytes, the correlation between $Q_{\text {ir-neg }}$ and $S_{\alpha}$ or $S_{\text {basal }}$ is much better than $S_{\text {edge }}$ in the whole negative potential range. This is different from the case of positive potential range, where $S_{\text {edge }}$ shows better correlation with $Q_{\text {ir-pos }}$ than $S_{\alpha}$ or $S_{\text {basal }}$ (Fig. S6). In $1 \mathrm{M} \mathrm{Et}_{4} \mathrm{NBF}_{4} / \mathrm{PC}$, the correlation between $Q_{\text {ir-neg }}$ and $S_{\text {basal }}$ is better than that between $Q_{\text {ir-neg }}$ and $S_{\alpha}$. Similar results are found in $1 \mathrm{M} \mathrm{Et}_{4} \mathrm{NBF}_{4} / \mathrm{AN}$ when the lower-limit potential is below $-1.3 \mathrm{~V}$, although the difference is small. In $1 \mathrm{M} \mathrm{Et}_{4} \mathrm{NBF}_{4} / \mathrm{PC}, R^{2}$ for $S_{\text {basal }}$ shows increase below $-1.2 \mathrm{~V}$, at which $Q_{\text {ir-neg }}$ starts increasing (Fig. $3 \mathrm{a}$ ). $R^{2}$ reaches the maximum at $-1.5 \mathrm{~V}$, and then it decreases. This decrease is mainly due to the gradual deviations of ZTC, $\mathrm{AAC}$ and $\mathrm{AACH} 2$ from the predicted trend line. In the case of $\mathrm{ZTC}$, we ascribe this phenomenon to the occurrence of pseudocapacitance. As is found in Fig. S2f, only ZTC shows noticeable redox peak around -1.4 to $-1 \mathrm{~V}$ when polarized to low potential below -1.6 $\mathrm{V}$. We have previously reported a high electrochemical reactivity of ZTC at a positive potential range in the $1 \mathrm{M} \mathrm{Et}_{4} \mathrm{NBF}_{4} / \mathrm{PC}$ electrolyte, in which oxygen-functional groups are introduced by the oxygen contained in PC.[22] Moreover, the oxygen-doped ZTC showed a large pseudocapacitance. Such highly reactive ZTC may also be electrochemically modified at the negative potential range. Because of the significant pseudocapacitance, $Q_{\mathrm{ir}-\mathrm{neg}}$ of ZTC deviates from the tendencies of other carbon materials especially below $-1.6 \mathrm{~V}$ (Fig. S7a-c), making the $R^{2}$ value decreased below $-1.6 \mathrm{~V}$ in Fig. 6a. However, the deviations of AAC and $\mathrm{AACH} 2$ cannot be explained from the present results, and some other unknown factors may also affect the degradation process. On the other hand, the appearance of pseudocapacitance is not intense in the $1 \mathrm{M} \mathrm{Et}_{4} \mathrm{NBF}_{4} / \mathrm{AN}$ electrolyte (Fig. S3f), and ZTC does not deviate very much from the tendency of the $Q_{\text {ir-neg }}-S_{\text {basal }}$ relation even below $-1.6 \mathrm{~V}$ (Fig. S7d-f). 


\subsection{Computational chemistry}

The experimental results pointed out that carbon basal planes are more reactive than carbon edge planes at the negative potential range. To further understand the results, we then investigated the electronic states and the overlapping of the molecular orbitals (MOs) for a carbon model (hexabenzocoronene) with a solvent molecule at the edge and on the basal plane of the model molecule by theoretical calculations (Fig. 7a). Acetonitrile (AN) was used as a representative of a reactant in electrolytes. As shown in Fig. 7b, the energy levels of initial HOMO state (147a) of both cases are quite similar; $-6.53 \mathrm{eV}$ on the basal plane and $-6.52 \mathrm{eV}$ at the edge site. However, there is a relatively lower lying state $(159 \mathrm{a},-3.31 \mathrm{eV})$ with an unoccupied MO delocalized over the components when AN is placed on the basal plane of the carbon model. Such a stabilization is not observed for the carbon model with AN at the edge (159a), and the reactant (AN) can only obtain electrons at a higher energy level $(160 \mathrm{a},-3.15 \mathrm{eV})$. This qualitatively indicates that the intermolecular electronic coupling could be stronger when AN is on the carbon basal plane, probably due to the more accessible $\pi$-electrons, and therefore the electron transfer from the negatively charged carbon model to the reactant on the basal plane $\left(\Delta E_{(147 \mathrm{a}-159 \mathrm{a})}=3.22 \mathrm{eV}\right)$ is more likely to occur than that at the periphery of the carbon model $\left(\Delta E_{(147 \mathrm{a}-160 \mathrm{a})}=3.37 \mathrm{eV}\right)$. The single-electron transfer could initiate the reductive degradation of reactants, leading to the cathodic irreversible current. Although the accurate prediction of thermodynamics and kinetics in electron transfer reactions could be achieved by the determination of the reaction coordinates that include the re-organization of solvents, the present calculations is in good agreement with the experimentally obtained results that show the higher reactivity of the carbon basal planes compared with the edge sites at cathodic conditions.

\section{Conclusions}


For the organic electrolytes $\left(1 \mathrm{M} \mathrm{Et}_{4} \mathrm{NBF}_{4} / \mathrm{PC}\right.$ or $\left.1 \mathrm{M} \mathrm{Et}_{4} \mathrm{NBF}_{4} / \mathrm{AN}\right)$ which are popularly used for commercial supercapacitors, the origin of degradation reactions at carbon electrode was investigated at a negative potential range. By using eight kinds of very different carbon materials, it is found that the degradation reactions mainly occur at the carbon basal planes rather than the edge sites. Such tendency is also supported by theoretical calculation for a model carbon-reactant system. The present results make a striking contrast to the positive potential case, where carbon edge sites are responsible for the electrochemical degradation.

\section{Acknowledgements}

This work was supported by JSPS KAKENHI (grant Nos. 17H01042 and 17H03097); the Dynamic Alliance for Open Innovation Bridging Human, Environment, and Materials program; and the Network Joint Research Centre for Materials and Devices. R. T. acknowledges the China Scholarship Council for the financial support. MICINN and FEDER (RTI2018-095291-B-I00) are acknowledged for financial support. The computations were performed using Research Center for Computational Science, Okazaki, Japan. The authors are thankful to Dr. Tracy Chuong for her kind suggestions on English writing.

\section{References}

[1] B.E. Conway. Electrochemical Supercapacitors-Scientific Fundamentals and Technological Applications, Kluwer Academic, New York, 1999.

[2] D. Weingarth, A. Foelske-Schmitz, R. Kotz. J. Power Sources 225 (2013) 84-88.

[3] R. Kotz, M. Carlen. Electrochim. Acta 45 (2000) 2483-2498.

[4] P. Simon, Y. Gogotsi. Nat. Mater. 7 (2008) 845-854.

[5] P. Azaïs, L. Duclaux, P. Florian, D. Massiot, M.-A. Lillo-Rodenas, A. Linares-Solano, J.- 
P. Peres, C. Jehoulet, F. Béguin. J. Power Sources 171 (2007) 1046-1053.

[6] M. Hahn, A. Würsig, R. Gallay, P. Novák, R. Kötz. Electrochem. Commun. 7 (2005) 925930.

[7] R. Kötz, M. Hahn, R. Gallay. J. Power Sources 154 (2006) 550-555.

[8] K. Nomura, H. Nishihara, N. Kobayashi, T. Asada, T. Kyotani. Energy Environ. Sci. 12 (2019) 1542 - 1549.

[9] D. Weingarth, H. Noh, A. Foelske-Schmitz, A. Wokaun, R. Kötz. Electrochim. Acta 103 (2013) 119-124.

[10] M.A. Sakka, H. Gualous, J.V. Mierlo, H. Culcu. J. Power Sources 194 (2009) 581-587.

[11] A. Izadi-Najafabadi, S. Yasuda, K. Kobashi, T. Yamada, D.N. Futaba, H. Hatori, M.

Yumura, S. Iijima, K. Hata. Adv. Mater. 22 (2010) E235-E241.

[12] A. Yoshida, I. Tanahashi, A. Nishino. Carbon 28 (1990) 611-615.

[13] C.H. Yang, Q.D. Nguyen, T.H. Chen, A.S. Helal, J. Li, J.K. Chang. ACS Sustainable Chem. Eng. 6 (2018) 1208-1214.

[14] S. Ishimoto, Y. Asakawa, M. Shinya, K. Naoi. J. Electrochem. Soc. 156 (2009) A563A571.

[15] M. Hahn, R. Kötz, R. Gallay, A. Siggel. Electrochim. Acta 52 (2006) 1709-1712.

[16] D. Cazorla-Amorós, D. Lozano-Castelló, E. Morallón, M.J. Bleda-Martínez, A. LinaresSolano, S. Shiraishi. Carbon 48 (2010) 1451-1456.

[17] M. Zhu, C.J. Weber, Y. Yang, M. Konuma, U. Starke, K. Kern, A.M. Bittner. Carbon 46 (2008) 1829-1840.

[18] R. Tang, K. Taguchi, H. Nishihara, T. Ishii, E. Morallón, D. Cazorla-Amorós, T. Asada, N. Kobayashi, Y. Muramatsu, T. Kyotani. J. Mater. Chem. A 7 (2019) 7480-7488.

[19] J. Li, Z. Xu, Z.A. Zhang. RSC Advances 8 (2018) 32188-32192.

[20] K. Xu, M.S. Ding, T.R. Jow. Electrochim. Acta 46 (2001) 1823-1827. 
[21] P.W. Ruch, D. Cericola, A. Foelske, R. Kötz, A. Wokaun. Electrochim. Acta 55 (2010) $2352-2357$.

[22] K. Nueangnoraj, H. Nishihara, T. Ishii, N. Yamamoto, H. Itoi, R. Berenguer, R. RuizRosas, D. Cazorla-Amorós, E. Morallón, M. Ito, T. Kyotani. Energy Storage Mater. 1 (2015) 35-41.

[23] H. Nishihara, T. Simura, S. Kobayashi, K. Nomura, R. Berenguer, M. Ito, M. Uchimura, H. Iden, K. Arihara, A. Ohma, Y. Hayasaka, T. Kyotani. Adv. Funct. Mater. 26 (2016) 6418-6427.

[24] R.D. Heidenre, W.M. Hess, L.L. Ban. J. Appl. Crystallogr. 1 (1968) 1-19.

[25] K. Kaneko, C. Ishii, M. Ruike, H. Kuwabara. Carbon 30 (1992) 1075-1088.

[26] K. Matsuoka, Y. Yamagishi, T. Yamazaki, N. Setoyama, A. Tomita, T. Kyotani. Carbon 43 (2005) 876-879.

[27] T. Ishii, S. Kashihara, Y. Hoshikawa, J. Ozaki, N. Kannari, K. Takai, T. Enoki, T. Kyotani. Carbon 80 (2014) 135-145.

[28] L.R. Radovic, B. Bockrath. J. Am. Chem. Soc. 127 (2005) 5917-5927.

[29] T. Enoki, K. Takai. Solid State Commun. 149 (2009) 1144-1150.

[30] N.R. Laine, F.J. Vastola, P.L. Walker. J. Phys. Chem. 67 (1963) 2030-2034.

[31] K. Xu, S.P. Ding, T.R. Jow. J. Electrochem. Soc. 146 (1999) 4172-4178.

[32] M.J. Frisch et al. Gaussian 09 Revision B.01, Gaussian Inc., Wallingford, CT, 2010.

[33] A.D. Becke. J. Chem. Phys. 107 (1997) 8554-8560.

[34] J.D. Chai, M. Head-Gordon. Phys. Chem. Chem. Phys. 10 (2008) 6615-6620.

[35] A. Klamt, G. Schuurmann. J. Chem. Soc., Perkin Trans. 2 (1993) 799-805.

[36] K. Kaneko, C. Ishii. Colloids Surf. 67 (1992) 203-212.

[37] D. Lozano-Castello, M.A. Lillo-Rodenas, D. Cazorla-Amoros, A. Linares-Solano. Carbon 39 (2001) 741-749. 


\section{Figure captions}

Fig. 1. Structure models of carbon materials used in this work. (a) Activated carbon, (b) carbon black, (c) zeolite-template carbon and (d) graphene mesosponge.

Fig. 2. (a) An example of calculating $Q_{\text {ir-neg: }}$ YP50F in $1 \mathrm{M} \mathrm{Et}_{4} \mathrm{NBF}_{4} / \mathrm{PC}$. $(\mathrm{b}, \mathrm{c}) \mathrm{CV}$ results of YP50F in (b) $1 \mathrm{M} \mathrm{Et}_{4} \mathrm{NBF}_{4} / \mathrm{PC}$ and (c) $1 \mathrm{M} \mathrm{Et}_{4} \mathrm{NBF}_{4} / \mathrm{AN}$. Scan rate: $1 \mathrm{mV} / \mathrm{s}$.

Fig. 3. $(\mathrm{a}, \mathrm{c})$ The change of $Q_{\mathrm{ir}-\mathrm{neg}}$ depending on the lower limit potential for the eight carbon materials. (b,d) The change of $Q_{\text {ir-pos }}$ depending on the upper limit potential. Electrolytes are (a,b) $1 \mathrm{M} \mathrm{Et}_{4} \mathrm{NBF}_{4} / \mathrm{PC}$ and (c,d) $1 \mathrm{M} \mathrm{Et}_{4} \mathrm{NBF}_{4} / \mathrm{AN}$.

Fig. 4. The plot of (a,c) $Q_{\text {ir-neg }}$ (lower limit potential of $-1.5 \mathrm{~V}$ ) and (b,d) $Q_{\text {ir-pos }}$ (upper limit potential of $1.3 \mathrm{~V}$ ) against the sum of $2 N_{\mathrm{H} 2}$ and $N_{\mathrm{CO}}$, corresponding to the amount of edge sites terminated by $\mathrm{H}$ and $\mathrm{CO}-$-evolution groups (phenol, ether, and carbonyl group), respectively.

Fig. 5. The plot of $Q_{\text {ir-neg }}$ against (a,b) $S_{\alpha},(\mathrm{c}, \mathrm{d}) S_{\text {edge }}$ and (e,f) $S_{\text {basal }}$ in (a,c,e) $1 \mathrm{M} \mathrm{Et}_{4} \mathrm{NBF}_{4} / \mathrm{PC}$ and $(\mathrm{b}, \mathrm{d}, \mathrm{f}) 1 \mathrm{M} \mathrm{Et}_{4} \mathrm{NBF}_{4} / \mathrm{AN}$.

Fig. 6. Correlation coefficient $\left(R^{2}\right)$ of $Q_{\text {ir-neg }}$ against carbon surfaces in different potential ranges. (a) In $1 \mathrm{M} \mathrm{Et}_{4} \mathrm{NBF}_{4} / \mathrm{PC}$ and (b) in $1 \mathrm{M} \mathrm{Et}_{4} \mathrm{NBF}_{4} / \mathrm{AN}$.

Fig. 7. (a) The structures for calculation: hexabenzocoronene as a carbon model and acetonitrile as a representative of a reactant in electrolyte. (b) Molecular orbital diagrams of a set of hexabenzocoronene (electron donor) and acetonitrile (electron acceptor) calculated at the unrestricted $\omega \mathrm{B} 97 \mathrm{XD} / 6-311++\mathrm{G}^{*}$ level of theory. Charge: -1 , Spin multiplicity: 2. 
Figure 1

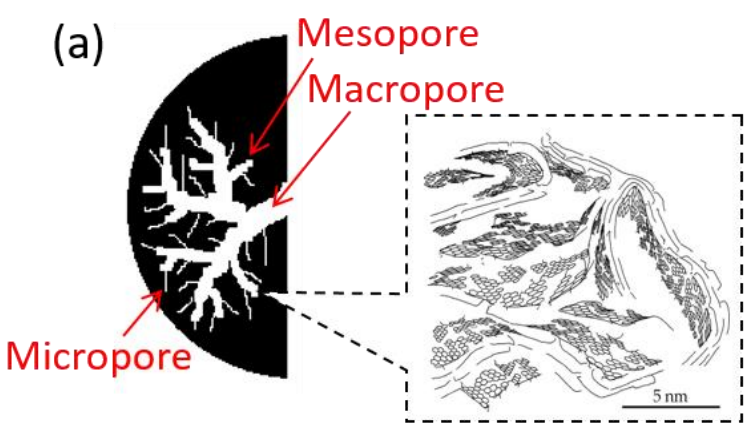

(b)

(c)

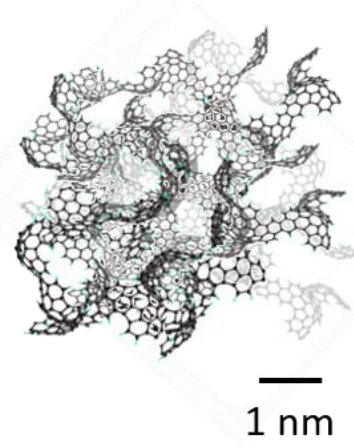

(d)
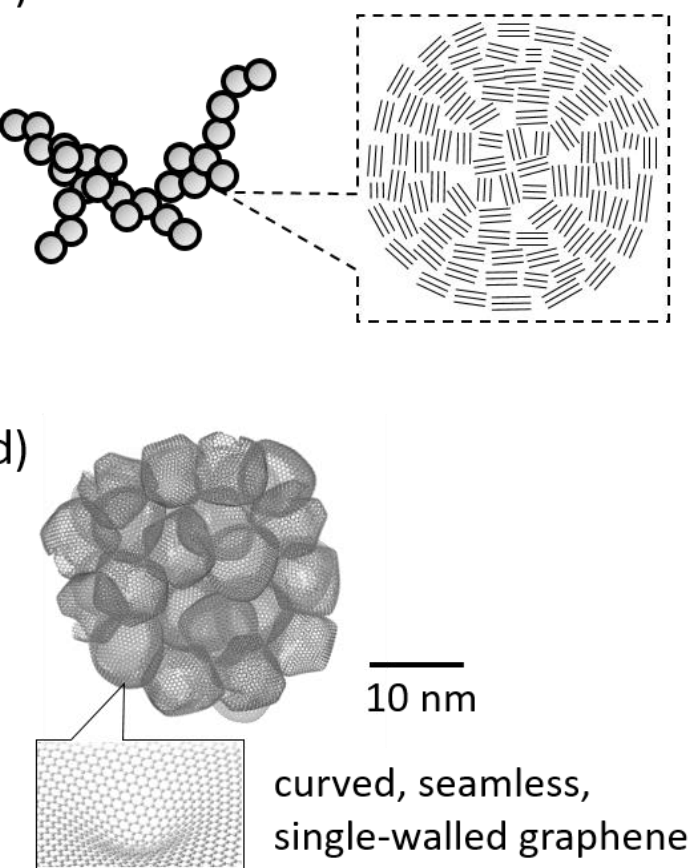
Figure 2
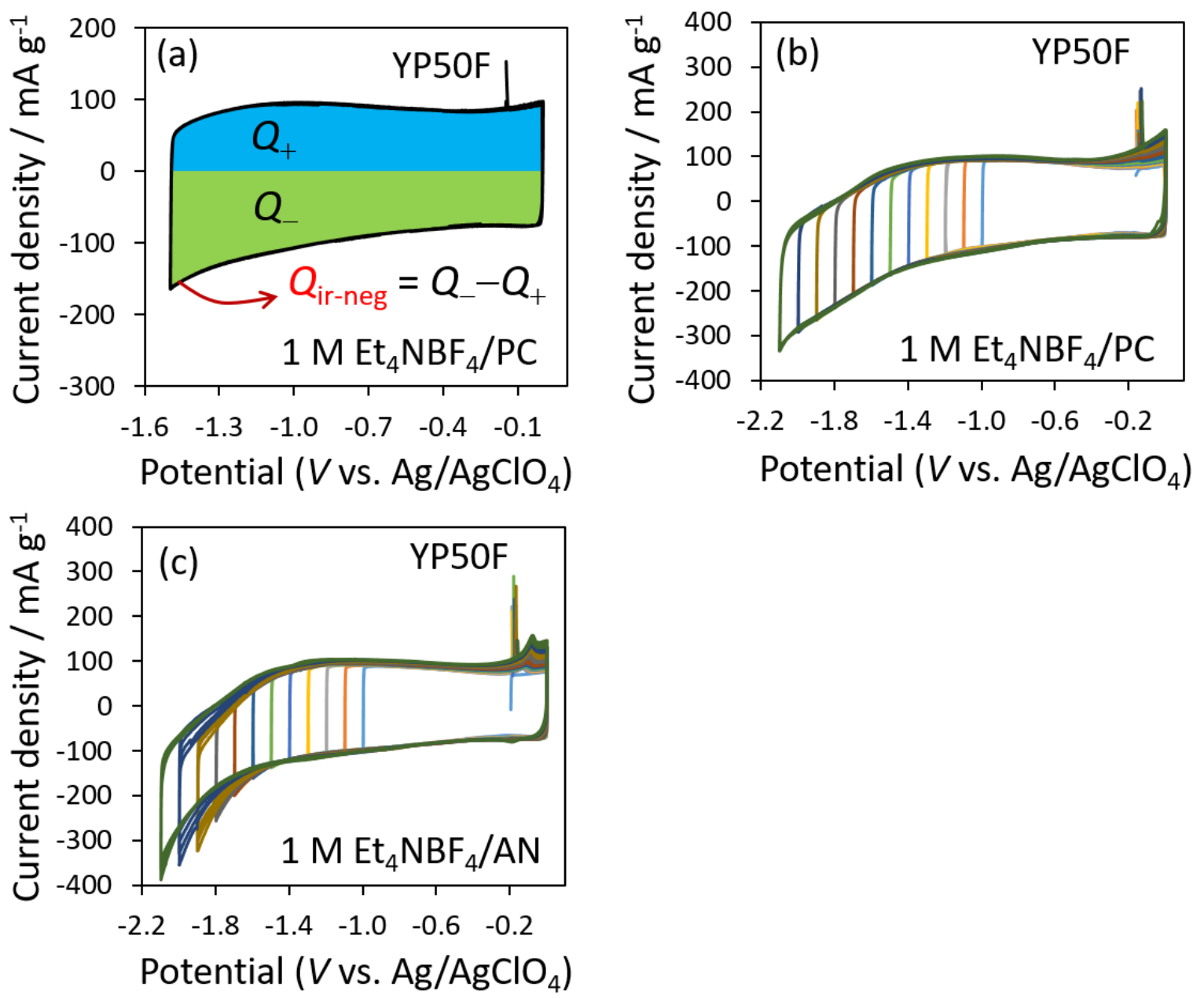
Figure 3
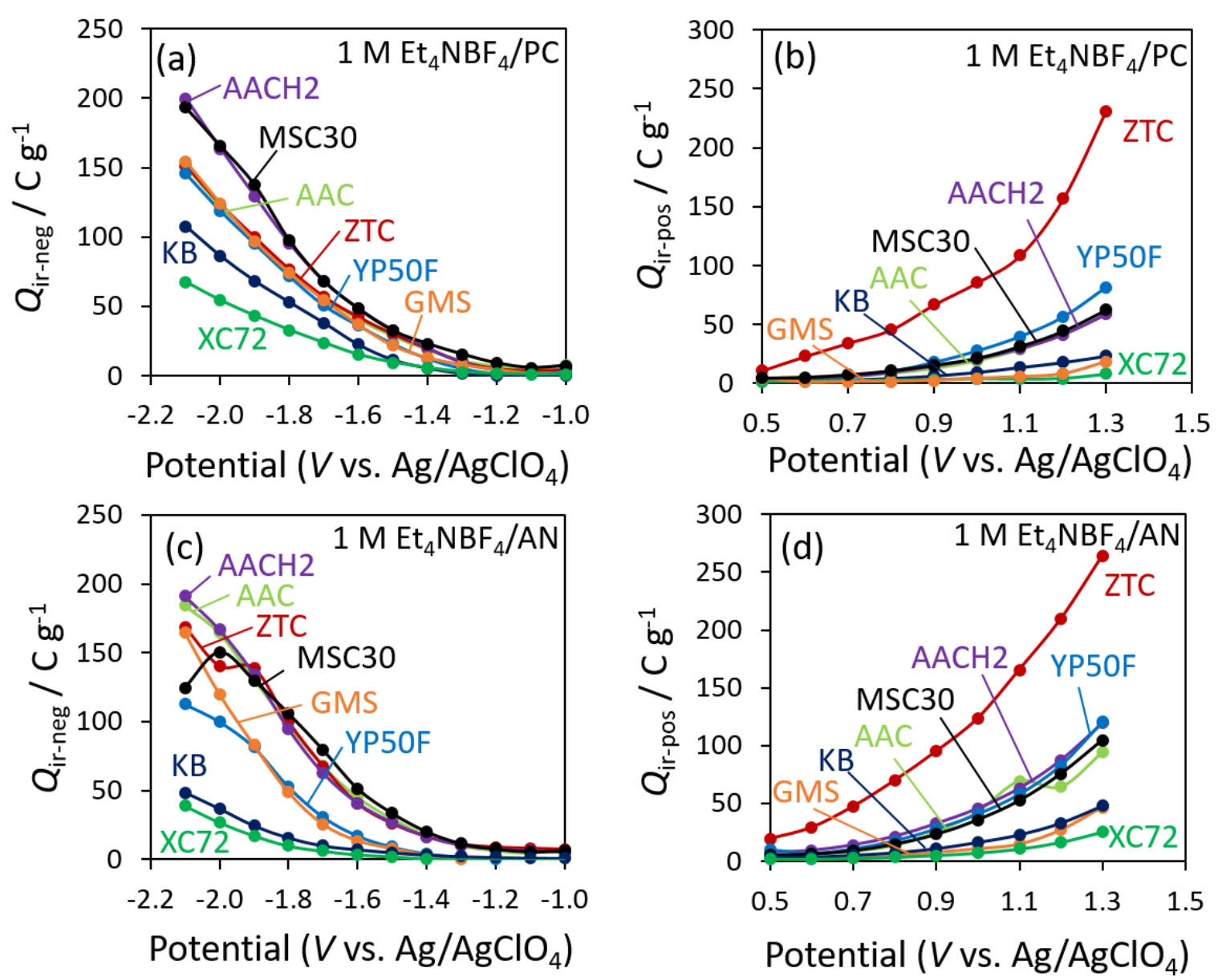
Figure 4
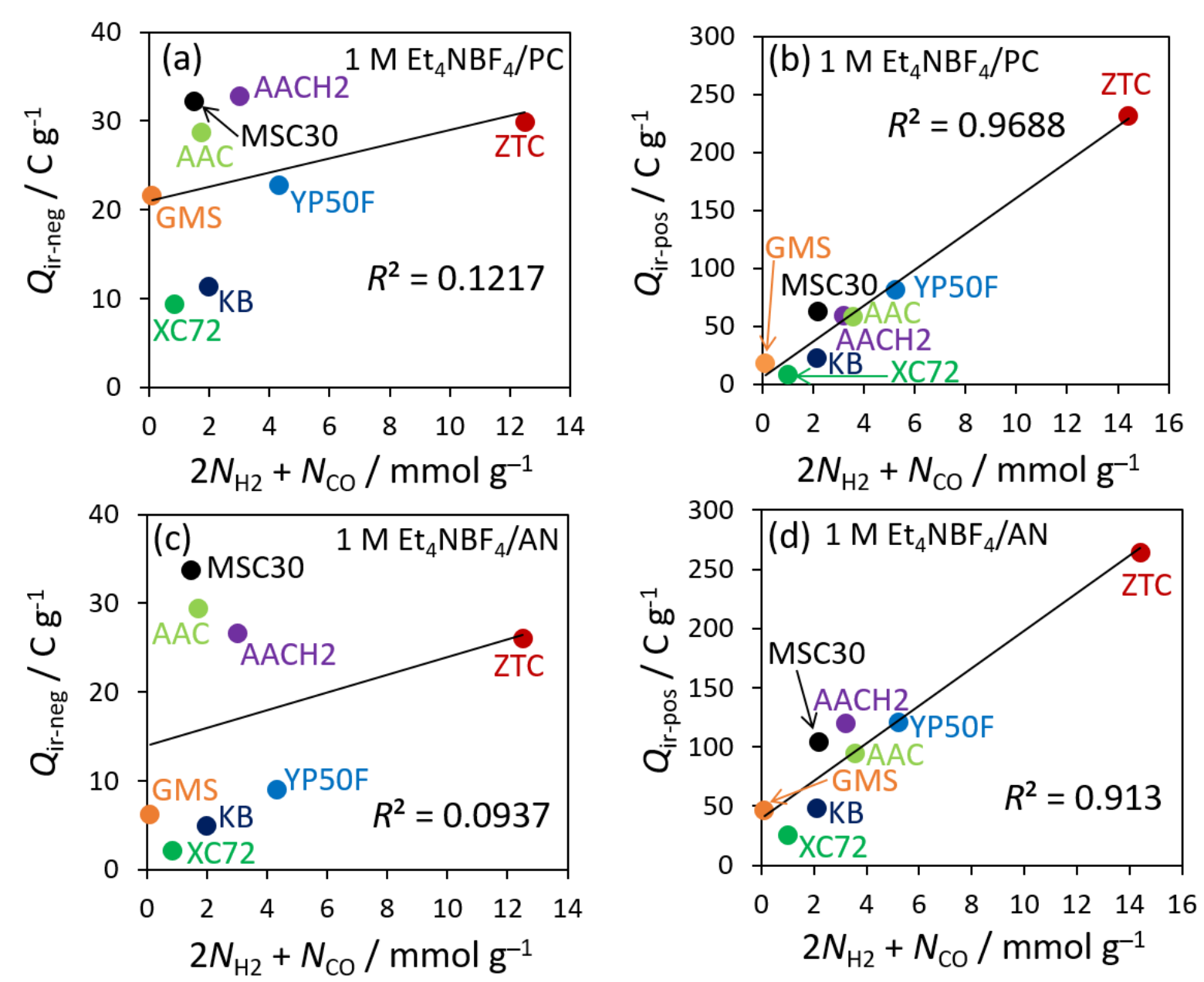
Figure 5
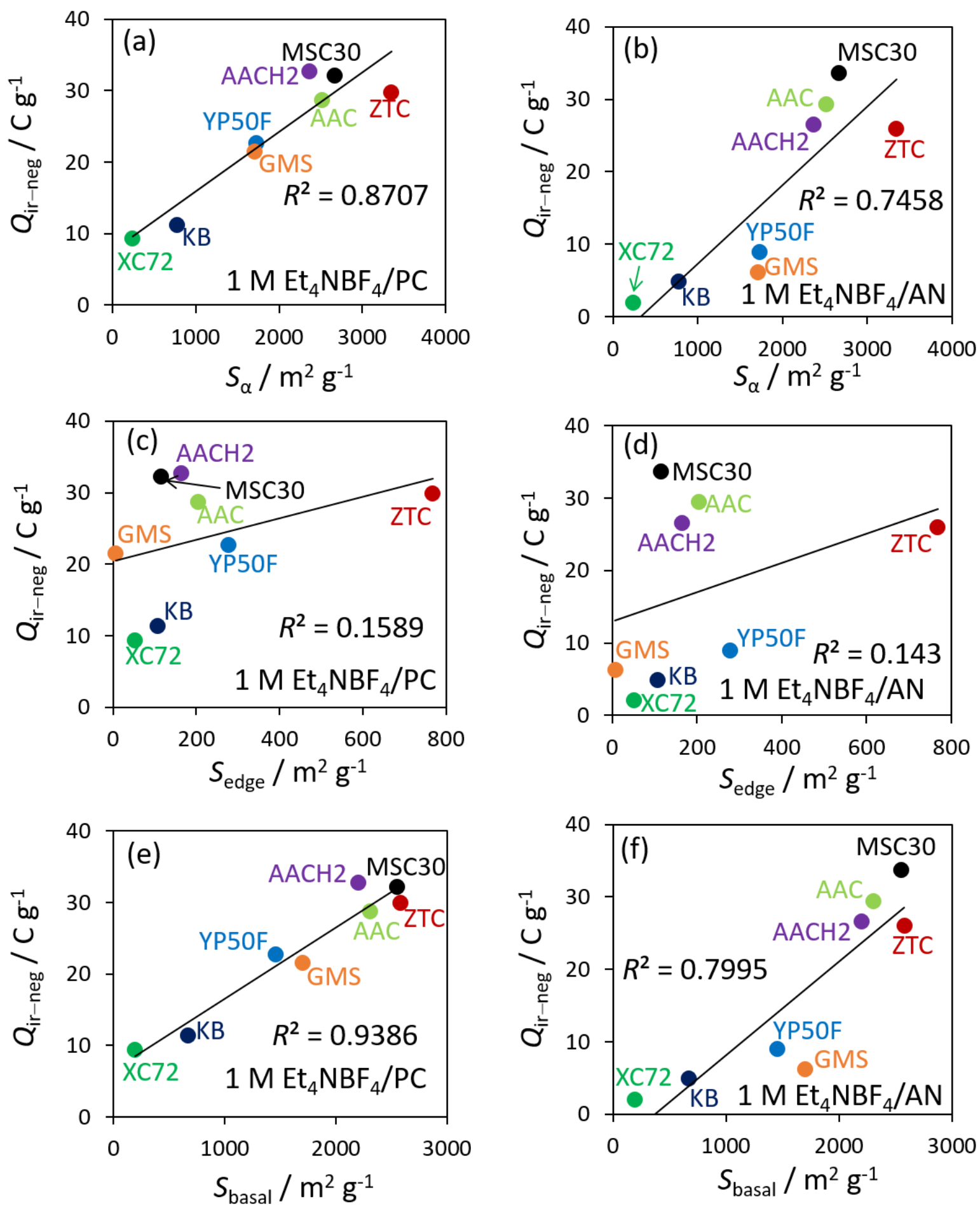
Figure 6
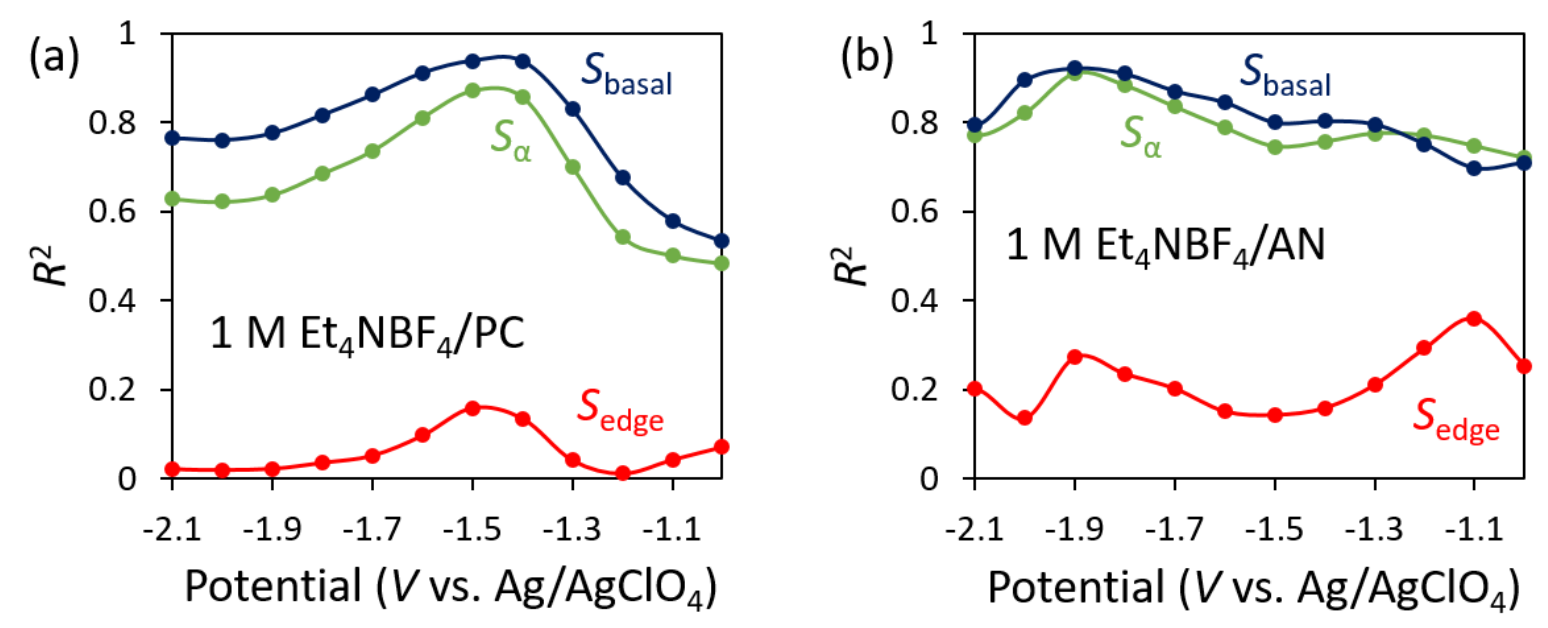
Figure 7

(a)

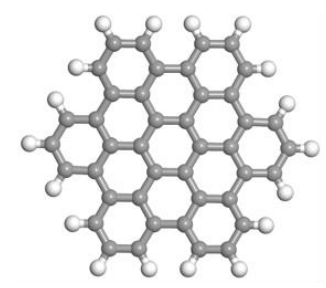

Hexabenzocoronene

(as a carbon model)

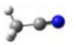

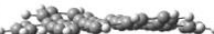

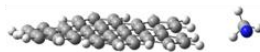

On the basal plane

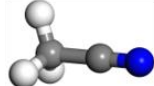

Acetonitrile (as a reactant)

At the edge
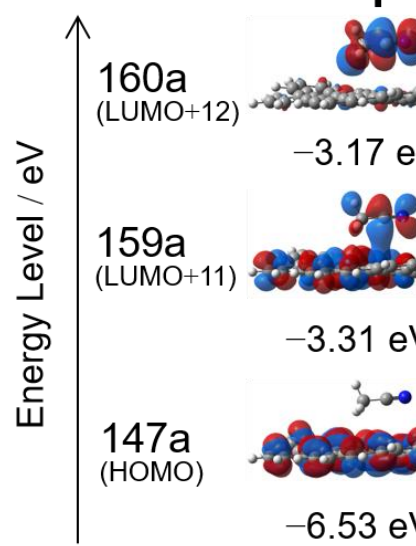

$160 a$

$147 a$

(HOMO)

; (b) On the basal plane At the edge

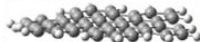

$-3.15 \mathrm{eV}$

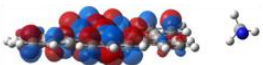

$-3.25 \mathrm{eV}$

$-3.31 \mathrm{eV}$

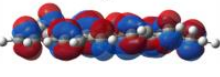

$-6.53 \mathrm{eV}$

$-6.52 \mathrm{eV}$

$\Delta E_{(147 a-159 a)}=3.22 \mathrm{eV} \quad \Delta E_{(147 a-160 a)}=\mathbf{3 . 3 7} \mathrm{eV}$ 


\section{Table captions}

Table. 1. A list of the eight carbon materials used in this work.

\begin{tabular}{|c|c|c|c|c|}
\hline Sample & Supplier & $S_{\alpha}^{a}\left[\mathrm{~m}^{2} \mathrm{~g}^{-1}\right]$ & $\begin{array}{c}N_{\text {edge }}{ }^{b} \\
{\left[\mathrm{mmol} \mathrm{g}^{-1}\right]}\end{array}$ & Remarks \\
\hline YP50F & $\begin{array}{l}\text { Kuraray Chemical } \\
\text { Co., Ltd. }\end{array}$ & 1731 & 5.6 & $\begin{array}{l}\text { A coconut-shell-derived steam-activated } \\
\text { carbon which is used for commercial } \\
\text { supercapacitors }\end{array}$ \\
\hline $\mathrm{AAC}$ & home made[37] & 2512 & 4.1 & $\begin{array}{l}\text { An anthracite-derived } \mathrm{KOH} \text {-activated } \\
\text { carbon }\end{array}$ \\
\hline $\mathrm{AACH} 2$ & home made[16] & 2363 & 3.3 & AAC treated with $\mathrm{H}_{2}$ at $850^{\circ} \mathrm{C}$ for $1 \mathrm{~h}$ \\
\hline MSC30 & $\begin{array}{l}\text { Kansai Coke and } \\
\text { Chemicals Co., Ltd. }\end{array}$ & 2662 & 2.3 & $\begin{array}{l}\text { A KOH-activated carbon, also known as } \\
\text { MAXSORB }^{\circledR}\end{array}$ \\
\hline $\mathrm{XC72}$ & Cabot Co., Ltd & 243 & 1.0 & Porous carbon black (VULCAN XC72) \\
\hline KB & $\begin{array}{l}\text { Lion Specialty } \\
\text { Chemicals., Ltd }\end{array}$ & 776 & 2.2 & $\begin{array}{l}\text { Hollow carbon black (Ketjen Black EC- } \\
300 \mathrm{~J})\end{array}$ \\
\hline ZTC & home made[22] & 3345 & 15.4 & $\begin{array}{l}\text { Zeolite-templated carbon with high } \\
\text { surface area and a large amount of edge } \\
\text { sites }\end{array}$ \\
\hline GMS & home made[23] & 1708 & 0.1 & $\begin{array}{l}\text { Graphene mesosponge with high surface } \\
\text { area and a very small amount of edge } \\
\text { sites }\end{array}$ \\
\hline
\end{tabular}

${ }^{a}$ Specific surface area calculated by the subtracting pore-effect method[25] based on the $\alpha_{\mathrm{s}}$ plot.

${ }^{b}$ Amount of edge sites $\left(N_{\text {edge }}\right)$ calculated by using the TPD results. Details can be found in 2.2 . Characterization. 
Table. 2. Surface areas of carbon materials used in this work.

\begin{tabular}{ccc}
\hline Sample & $S_{\text {edge }}\left[\mathrm{m}^{2} \mathrm{~g}^{-1}\right]^{a}$ & $S_{\text {basal }}\left[\mathrm{m}^{2} \mathrm{~g}^{-1}\right]^{b}$ \\
\hline YP50F & 277 & 1454 \\
AAC & 205 & 2307 \\
AACH2 & 165 & 2198 \\
MSC30 & 115 & 2547 \\
XC72 & 52 & 191 \\
KB & 107 & 669 \\
ZTC & 768 & 2577 \\
GMS & 7 & 1701
\end{tabular}

${ }^{a}$ Edge-plane area calculated by using the results of $N_{\text {edge }}$ and assuming that the area occupied by each edge site is $0.083 \mathrm{~nm}^{2}$.

${ }^{b}$ Basal-plane surface area by subtracting $S_{\text {edge }}$ from $S_{\alpha}$. 